\title{
Effects of Freeze Vacuum Drying Combined with Hot Air Drying on the Sensory Quality, Active Components, Moisture Mobility, Odors, and Microstructure of Kiwifruits
}

\author{
Lihui Zhang $\mathbb{D}^{\mathbb{D}}{ }^{1,2,3}$ Yu Qiao ${ }^{\mathbb{D}},{ }^{1}$ Chao Wang $\mathbb{D},{ }^{3}$ Li Liao, ${ }^{1}$ Lu Liu, ${ }^{1}$ Defang Shi, ${ }^{1}$ Kejing An, ${ }^{2}$ \\ Jianzhong $\mathrm{Hu}^{3}$ and Qing $\mathrm{Xu}^{4}$ \\ ${ }^{1}$ Institute for Agricultural Products Processing and Nuclear-agricultural Technology, Hubei Academy of Agricultural Sciences, \\ Wuhan 430064, China \\ ${ }^{2}$ The Sericulture \& Farm Produce Processing Research Institute of Guang Dong Academy of Agricultural Sciences, \\ Guangzhou 510642, China \\ ${ }^{3}$ Key Laboratory of Fermentation Engineering (Ministry of Education), Hubei Key Laboratory of Industrial Microbiology, \\ Hubei Provincial Cooperative Innovation Center of Industrial Fermentation, Hubei University of Technology, \\ Wuhan 430068, China \\ ${ }^{4}$ Wuhan Institute of Design and Sciences, Wuhan 430205, China
}

Correspondence should be addressed to Yu Qiao; qiaoyu412@sina.com and Chao Wang; 14352016@qq.com

Received 29 September 2018; Revised 16 January 2019; Accepted 29 January 2019; Published 7 March 2019

Academic Editor: Susana Fiszman

Copyright (c) 2019 Lihui Zhang et al. This is an open access article distributed under the Creative Commons Attribution License, which permits unrestricted use, distribution, and reproduction in any medium, provided the original work is properly cited.

In this study, freeze vacuum drying (FVD), hot air drying (AD), and FVD combined with AD (FVD-AD) were used to dry kiwifruits. Dried products were analyzed comprehensively on their sensory quality, active components, moisture mobility, odors, and microstructure. Results showed that the FVD-AD saved time by $38.22 \%$ compared with FVD while maintaining an acceptable product quality. The antioxidant properties of FVD-AD were lower than those of FVD but significantly higher than those of AD. Moreover, compared with FVD products, FVD-AD products were moderately hard $(5252.71 \pm 33.53 \mathrm{~g})$ and improved in color, bound water, and microstructure. Additionally, FVD-AD consumed lesser drying time and energy than FD. According to cluster analysis, the odors of FVD-AD products were similar to those of the fresh ones. Principal component analysis of physicochemical and drying cost indicated that FVD-AD was a promising processing technique for functional kiwifruit snacks.

\section{Introduction}

Originated in Asia, kiwifruits became popular worldwide due to its sensory and nutritional properties, such as a high level of fibers and bioactive compounds with antioxidant activity. However, kiwifruits were prone to a series of biotic and abiotic stresses, which caused physiological and biochemical changes, leading to fruit quality deterioration, nutrient loss, and decay. For spoilage prevention, chemical reactions must be reduced and shelf life extended.

Hot air drying $(\mathrm{AD})$ was the most common drying method in food production because of its affordability. However, long drying periods often result in inferior product quality due to nutrient losses [1]. Meanwhile, freeze vacuum drying (FVD) was another drying method to remove water from a frozen solution by sublimation under reduced pressure [2], giving rise to high-quality dried products [3]. The main difference with respect to hot air drying was that water was not removed by evaporation but by sublimation from a completely frozen product. The pore structure produced by freeze vacuum drying (FVD) products contributed to brittle texture and rapid rehydration [4]. Therefore, developing FVD technique can reduce the production cost without compromising product quality was necessary [5]. The sublimation drying was the key step in the FVD process, and it affected the quality of the products directly [6]. However, the desorption process took up nearly half the time of the whole process although it can only 
remove a little water. In order to guarantee the quality of the products and reduce drying time, many different combinations of drying methods have been recently used to dehydrate fruits and vegetables and avoid the disadvantages of freeze vacuum drying method, such as high energy consumption, low drying efficiency, and high cost. For example, to achieve the same moisture content in products, the production cost of freeze drying can be $200-500 \%$ higher than that of hot air drying [5]. Combining hot air and freeze vacuum drying in fruits and vegetables has been reported to improve product quality in the form of better aroma, faster and better rehydration, considerable savings in energy, and much shorter drying times, compared with hot air drying [7]. Donsì et al. [8] dried apples, potatoes, and carrots by freeze vacuum drying (FVD) combined with $\mathrm{AD}$ (FVD-AD), which can potentially obtain high-quality dehydrated fruits and vegetables. Pei et al. [9] indicated that the energy consumption of FVD-AD reduced by $34.51 \%$ compared with the FVD method. High temperatures or long drying times in conventional air drying can cause serious damage to product flavor, color, and nutrients and reduce the rehydration capacity of the dried product. The combination of hot air and vacuum freeze drying had high-quality characteristics because of vacuum freeze drying. Saxena et al. [10] reported that jackfruit bulb slices dried by FVD-AD produced a comparatively better quality crisps from jackfruit bulb slices in terms of rehydration ratio, shrinkage, instrumental texture, color values, and sensory scores, as compared with the AD crisps. Dehydrated bamboo shoot slices from the combined FVD-AD drying were superior to those from single AD drying in terms of sensory, nutrition, and cell structure [7]. In combination drying, the loss of tocopherol content was reduced and the retention of carotenoid content was increased compared to the fully hot air-dried samples [11]. This method had been applied in food drying, such as cherry tomato [12], apple [13], and cabbage [14]. However, to the best of our knowledge, no reports have been available on whether FVD-AD dries kiwifruit. Fruit drying involved several physicochemical changes in water activity $\left(a_{\mathrm{w}}\right)$, color, structure, odors, and nutraceutical components [15]. Therefore, finding an optimal drying method is immensely important.

In order to guarantee the quality of the products and reduce drying time, $\mathrm{AD}$ was used to replace the desorption process of the FVD in our research. Three different kinds of drying methods: freeze vacuum drying (FVD), hot air drying $(\mathrm{AD})$, and freeze vacuum drying combined with hot air drying(FVD-AD) were used to dry kiwifruit slices. We investigated and discussed the effects of three drying processes on several antioxidant properties (ascorbic acid content (AA) and total phenolic and flavonoid contents) and sensory qualities of kiwifruits (hardness, water activity, color, water distribution of each method, microstructure, and odor by an electronic nose in the flavor profile).

\section{Materials and Methods}

2.1. Raw Materials. Fresh kiwifruits (gold-colored kiwi, Jinyan, Shanxi) were purchased from a local supermarket
(Wuhan), with an initial moisture content of $81.78-86.26 \%$ (wet basis). Kiwifruits were washed, cut into slabs at $5 \mathrm{~mm}$ thick without peeling, and then dehydrated.

2.2. Drying Methods. Kiwifruits $(5 \mathrm{~kg}$ ) were subjected to three different drying methods, respectively, until the moisture contents were below $4 \%$ (dry weight).

2.2.1. Freeze Vacuum Drying (FVD). The FVD process was performed using a laboratory-scale freeze dryer (Scientz18ND, Martin Christ, Germany). Kiwifruits were spread uniformly on the metal trays and then frozen at $-40^{\circ} \mathrm{C}$ followed by freeze drying for $42 \mathrm{~h}$ under the condition of absolute pressure of $20-40 \mathrm{~Pa}$, chamber temperature of $20^{\circ} \mathrm{C}$, and condenser temperature of $-60^{\circ} \mathrm{C}$.

2.2.2. Hot Air Drying (AD). Kiwifruits were spread uniformly on the metal trays and dried using a laboratory electric oven dryer (DHG-9123A, Shanghai Jinghong Test Equipment Co., Ltd., Shanghai, China). The AD processing parameters were set as air temperature of $70^{\circ} \mathrm{C}$ and air velocity of $0.1 \mathrm{~m} / \mathrm{s}$ for $24 \mathrm{~h}$, and the limit maximum internal temperature of samples was $60^{\circ} \mathrm{C}$.

2.2.3. Freeze Vacuum Drying-Hot Air Drying (FVD-AD). Samples were first dried by FVD for $10 \mathrm{~h}$ (the moisture content of the samples was $30 \pm 5 \%$ ) and then processed by $\mathrm{AD}$ for $2 \mathrm{~h}$ (the moisture content was $<4 \%$ ).

2.3. Determination of Specific Energy Requirements, Color, Texture, Moisture Content, and Water Activity $\left(a_{w}\right)$. The energy required for drying each kilogram of kiwifruit was calculated by

$$
E_{\mathrm{kg}}=\frac{E_{\mathrm{t}}}{W_{0}} \times 1000,
$$

where $E_{\mathrm{kg}}$ is the specific energy requirement $(\mathrm{kWh}), E_{\mathrm{t}}$ is the total energy consumed (kWh), and $W_{0}$ is the initial weight of the kiwifruit sample (g).

A color meter (Model CR-400, Konica Minolta Holdings, Inc. China) was used to measure the color of the kiwifruits, with a white reference tile used for calibration. The hunter-Lab units $L^{*}, a^{*}$, and $b^{*}$ were used to define the colors, which were expressed in terms of hue angle $\left(h^{\circ}\right)$. Color changes between the fresh and dried samples $(\Delta E)$ were measured 5 times.

A texture analyzer (TA.XT 2i/50, Stable Micro System Ltd., Surrey, UK) with a P/2 probe was used for test analysis. The probe was used to measure the maximum force required to penetrate an individual rehydrated piece of kiwifruit, to a depth of $30 \%$, positioned horizontally over a heavy duty platform, with 5,1 , and $5 \mathrm{~mm} / \mathrm{s}$ as the prespeed, test-speed, and postspeed settings, respectively. For each experiment, the hardness (g) was recorded.

Moisture content was determined by the oven method. The water activity of the samples was measured using a water 
activity meter (LabMaster-aw neo, Novasina, Switzerland) at a constant temperature of $20 \pm 1^{\circ} \mathrm{C}$. A total of three readings were made for each sample.

2.4. Determination of Ascorbic Acid Content (AA). The amount of AA was determined by means of a test, using Folin-Ciocalteu reagent, derived from what was first proposed by Jagota and Dani [16]. The results were reported as milligrams of AA (mgAA) per $100 \mathrm{~g}$ of dried matter.

\subsection{Determination of the Total Flavonoid Content (TFC) and} $D P P H$ Radical-Scavenging Assay. TFC was measured as described by An et al. [17], with minor modifications. Extract of kiwifruit by ethanol $(1 \mathrm{~mL})$ and rutin standard solutions were mixed, respectively, with $1 \mathrm{~mL}$ of $5 \% \mathrm{NaNO}_{2}$, and the total volume was made up to $12.5 \mathrm{~mL}$ with $70 \%$ ethanol and then allowed to mix for $5 \mathrm{~min}$. After that, $1 \mathrm{~mL}$ of $10 \% \mathrm{Al}\left(\mathrm{NO}_{3}\right)_{3}$ was added and allowed to stand for $6 \mathrm{~min}$. The further $5 \mathrm{~mL}$ of $1 \mathrm{~mol} / \mathrm{L} \mathrm{NaOH}$ was added, and the total volume was made up to $25 \mathrm{~mL}$ with $70 \%$ ethanol. The absorbance of the reaction mixture was read at $510 \mathrm{~nm}$.

DPPH radical-scavenging ability of the kiwifruit extracts was determined using previously described studies [18], with modifications. Briefly, $3.0 \mathrm{~mL}$ of $0.065 \mathrm{mmol} / \mathrm{L} \mathrm{DPPH}$ and $0.5 \mathrm{~mL}$ of $70 \%$ ethanol were mixed. Then, $3.0 \mathrm{~mL}$ of $0.065 \mathrm{mmol} / \mathrm{L} \mathrm{DPPH}$ and $0.5 \mathrm{~mL}$ of extract of kiwifruit by ethanol were mixed. Finally, $3.0 \mathrm{~mL}$ of $70 \%$ ethanol and $0.5 \mathrm{~mL}$ of extract of kiwifruit by ethanol were mixed, and after standing for $30 \mathrm{~min}$, the absorbance of the mixture was measured at $517 \mathrm{~nm}$.

2.6. Low-Field Nuclear Magnetic Resonance (LF-NMR) Measurements. The relaxation times using NMR (Niumag Co., Ltd., Shanghai, China) were evaluated to perform LFNMR measurements. Approximately $4 \mathrm{~g}$ of samples were placed in cylindrical glass tubes $(2 \mathrm{~cm}$ diameter, $4 \mathrm{~cm}$ high). The glass tubes with samples were placed into a CTHI-100 B/ $150 \mathrm{~B} / 250 \mathrm{~B}$ box at $25^{\circ} \mathrm{C}$ (STIK Co., Ltd., Shanghai, China). Transverse relaxation times $\left(T_{2}\right)$ were measured using the Carr-Purcell-Meiboom-Gill (CPMG) pulse sequence. The parameters of CPMG were as follows: corresponding resonance frequency (SF) for protons, $20 \mathrm{MHz}$; spectral width (SW), $100 \mathrm{kHz}$; echo time (TE), $0.250 \mathrm{~ms}$; pulse widths at $90^{\circ}$ (P1) and $180^{\circ}$ (P2), 8.0 and $15.52 \mu \mathrm{s}$, respectively; waiting time (TW), $800 \mathrm{~ms}$; radio frequency delay time (RFD), $0.08 \mathrm{~ms}$; analog gain (RG1), $20 \mathrm{db}$; and digital gain (DRG1), set 3. Data from 3,000 echoes were acquired as 32 scan repetitions.

2.7. Electronic Nose (E-Nose) Analysis. The E-nose system composed of a measuring chamber with 18 metal oxide sensors (Alpha M.O.S., FOX4000, France). This equipment was used to distinguish the differences on the aroma profile of kiwifruits. Approximately $2 \mathrm{~g}$ of samples were placed into a $5 \mathrm{~mL}$ glass vessel that was immediately sealed by a metal screw cap. Firstly, the samples were balanced after $300 \mathrm{~s}$ of equilibration at $60^{\circ} \mathrm{C}$, and the headspace reached a steady state. The injection speed was $150 \mathrm{~mL} / \mathrm{min}$ to ensure an injection period of $1 \mathrm{~s}$. Filtered and dried air (purity $>99.999 \%$ ) with a flow rate of $150 \mathrm{~mL} / \mathrm{min}$ was used as a carrier gas for E-nose detection. The data acquisition lasted for $120 \mathrm{~s}$, and system rebalance needs $300 \mathrm{~s}$. For each sample, the E-nose detection was performed three times under the same condition.

2.8. Microstructural Analysis. Microstructures of the longitudinal section of FVD, $\mathrm{AD}$, and FVD-AD kiwifruit samples were acquired using a field emission scanning electron microscope (FE-SEM) (SU8010, Hitachi, Tokyo, Japan) at an accelerating voltage of $1.0 \mathrm{kV}$. The SEM micrographs were obtained at $30 \times$ and $100 \times$ magnifications.

2.9. Experimental Design and Statistical Analysis. The experiment was designed as a randomized complete block, and individual kiwifruits were the experimental unit for quality. Figure 1 provides an overview of the order of preparation and testing. All experiments were run at least three times, and the data were expressed as mean \pm standard deviation (SD). Statistical analyses were performed by Microcal Origin 9.0 software (Microcal Software, Inc., Northampton, USA). Analysis of variance (ANOVA) and Duncan's multiplerange test $(p<0.05)$ were used to evaluate the differences among the samples. XLSTAT-Excel was used to perform principal component analysis (PCA).

\section{Results and Discussion}

3.1. Effect of the Drying Method on Color Parameters. The fruit color can be easily changed during the drying process; this change was one of the negative quality attributes that affect customers' perceptions of dried products [19]. In kiwifruits, significant differences in $L^{*}, a^{*}$, and $b^{*}$ values between the fresh and dehydrated samples were observed $(p<0.05)$ (Table 1). Fresh kiwifruits were characterized by high luminosity, with a tendency to green and yellow. Regarding $a^{*}$ (redness) and $b^{*}$ (yellowness), higher $L^{*}$ and lower $a^{*}$ values were found in samples dried by FVD and FVD-AD, as compared with those samples dried by AD. Similarly, Lin et al. [20] observed a higher $L^{*}$ value for carrot slices under FVD than that for those under AD. However, the $b^{*}$ value of dried kiwifruits was higher than that of fresh. The color of vegetables was determined by natural color compounds that can be oxidized during the drying treatment, and the important factors accelerating degradation were high temperature and presence of oxygen [21]. The moisture migration rate can reflect the changes of color in drying samples. During drying of kiwifruits, the moisture of samples' surface was evaporated gradually and the internal moisture transferred from the center of the samples to the surface. The color of the dried fruit generally changed because of browning reaction, which was always related to the Maillard reaction [22]. The total color difference $(\Delta E)$ demonstrated that the color closely follows fresh kiwifruits. Overall, drying using FVD-AD resulted in the lowest total color change $(\Delta E)$, while the highest total color $(\Delta E)$ change 


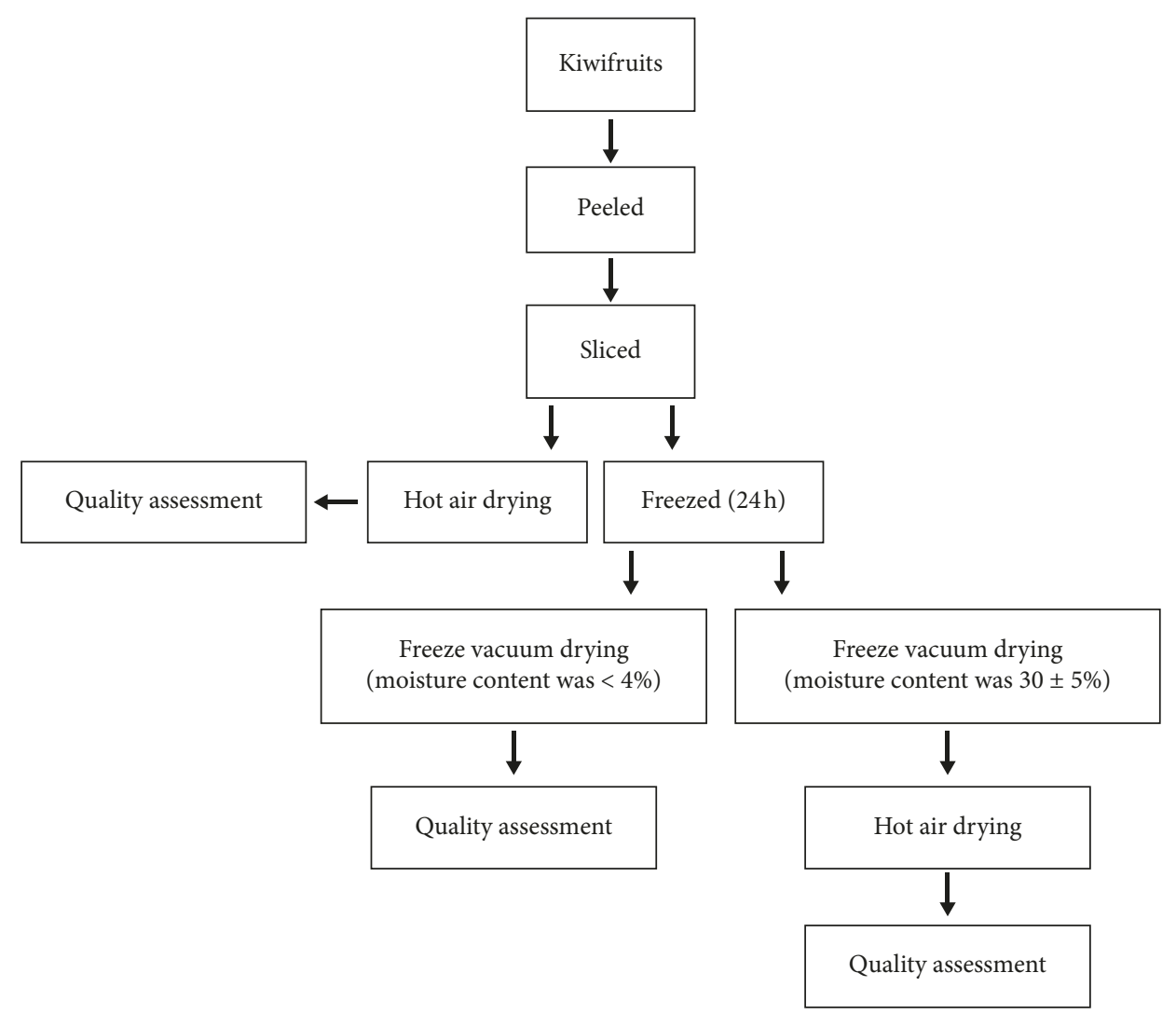

FIgURE 1: Flow diagram of kiwifruit samples preparation and testing.

TABLE 1: Color parameters of kiwifruits samples dried by different drying methods.

\begin{tabular}{|c|c|c|c|c|c|}
\hline \multirow{2}{*}{ Drying method } & \multicolumn{5}{|c|}{ Surface color } \\
\hline & $L^{*}$ & $a^{*}$ & $b^{*}$ & $\Delta E$ & $h^{\circ}$ \\
\hline FVD & $62.45 \pm 1.42^{\mathrm{b}}$ & $1.34 \pm 0.22^{\mathrm{c}}$ & $31.54 \pm 1.49^{b}$ & $10.27 \pm 0.25^{\mathrm{b}}$ & $82.71 \pm 1.54^{\mathrm{c}}$ \\
\hline $\mathrm{AD}$ & $55.88 \pm 0.35^{\mathrm{c}}$ & $3.05 \pm 0.18^{\mathrm{a}}$ & $38.73 \pm 1.36^{\mathrm{a}}$ & $12.28 \pm 0.52^{\mathrm{a}}$ & $76.00 \pm 1.08^{\mathrm{d}}$ \\
\hline FVD-AD & $60.30 \pm 1.17^{\mathrm{b}}$ & $0.97 \pm 0.20^{\mathrm{d}}$ & $28.64 \pm 0.79^{b}$ & $6.55 \pm 0.14^{\mathrm{c}}$ & $88.16 \pm 1.12^{b}$ \\
\hline Fresh & $67.62 \pm 0.51^{\mathrm{a}}$ & $2.42 \pm 0.32^{\mathrm{b}}$ & $24.36 \pm 0.21^{\mathrm{c}}$ & 0 & $97.30 \pm 2.24^{\mathrm{a}}$ \\
\hline
\end{tabular}

Note. Data are shown as the mean $\pm \mathrm{SD}(n=3)$. Means within a column with the same letter are not significantly different as indicated by Duncan's multiplerange test $(p<0.05)$. FVD: freeze vacuum drying; AD: air drying; FVD-AD: combined drying consisting of freeze vacuum drying and air drying.

of kiwifruit slices was observed during AD. This was clearly depicted in the images of the fresh and dried samples (Figure 2). As observed from the image, the color of samples dried using FVD-AD looked very similar to that of the fresh sample, whereas the color of samples dried using FVD and $\mathrm{AD}$ was sharply different from that of the fresh sample. This may be due to the vacuum environment during FVD and FVD-AD. However, oxidative reactions and enzymatic browning possibly occurred during $\mathrm{AD}$ process, making the products turn brown easily [23]. The $h^{\circ}$ value showed significant differences $(p<0.05)$ among fresh and dried kiwifruits. The fresh and FVD-AD kiwifruits were close to kelly, and FVD and AD were close to orange. Hence, the color of FVD-AD was the closest to fresh kiwifruits. Moisture Content, and Water Activity. The moisture content and water activity of kiwifruits manufactured with different drying methods are shown in Table 2. Significant differences were observed among drying time, hardness, moisture content, and water activity of the selected drying methods $(p<0.05)$. The initial moisture content of fresh kiwifruit was at $87.55 \% \pm 1.64 \%$, dry basis. Finally, the moisture content of kiwifruit was about $3.00 \%$. The $a_{\mathrm{w}}$ values of AD, FVD, and FVD-AD kiwifruits were low, ranging among 0.3048 and 0.3335 compared with fresh samples $(0.9927)$. If the $a_{\mathrm{w}}$ value was below 0.60 , then the growth of microbes and lipid oxidation in food products were totally restrained during storage $[24,25]$. As shown in Table 2, FVD-AD significantly reduced the drying time by $38.22 \%(p<0.05)$, compared with the FVD alone; FVD-AD also consumed lesser energy than in FVD. This result could be due to the slower vaporization of moisture in $\mathrm{FD}$ than in $\mathrm{AD}$. Mass transfer within the kiwifruits should be rapid during $\mathrm{AD}$ because a large vapor pressure was produced by air on the surface of 


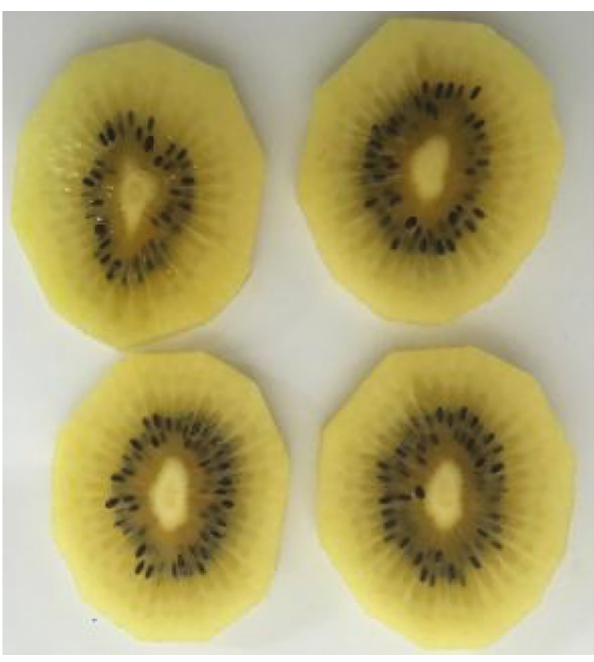

(a)

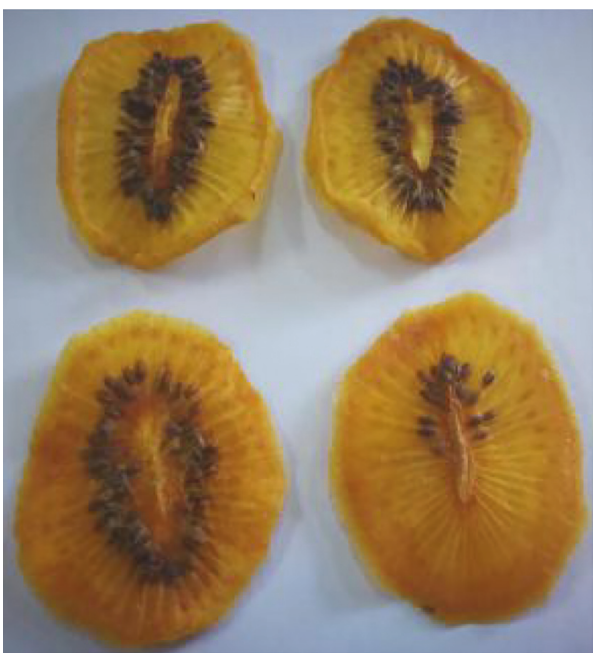

(c)

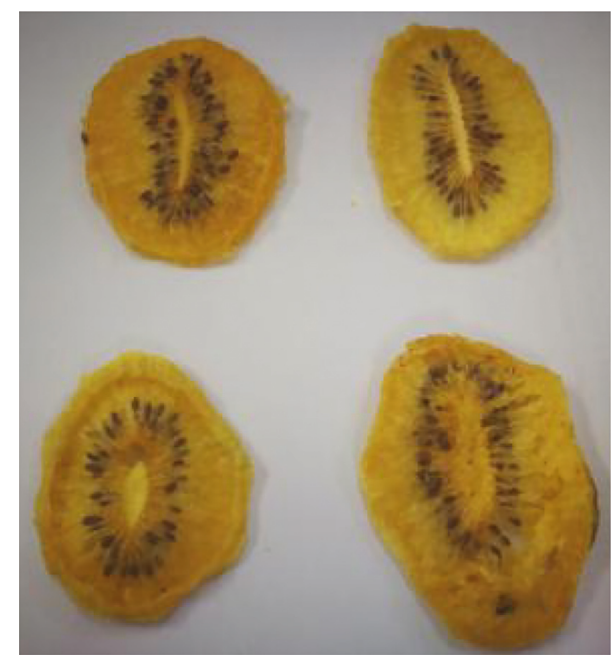

(b)

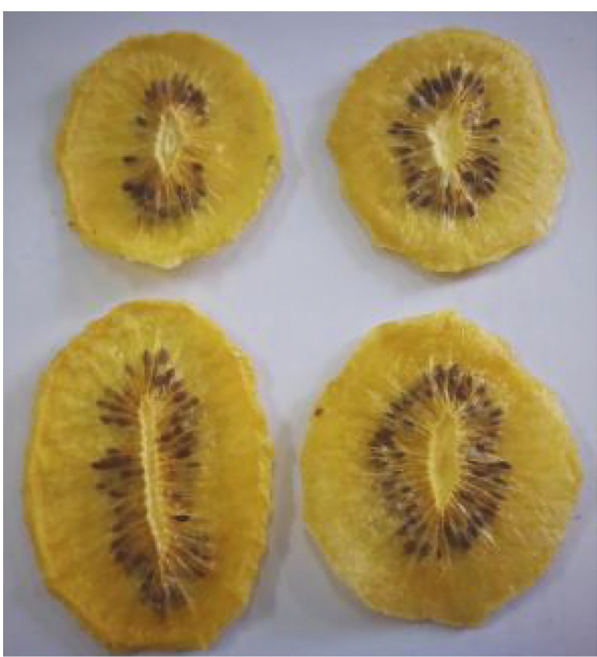

(d)

FIGURE 2: Images of a fresh kiwifruit sample (a) and kiwifruit samples dried by FVD (b), AD (c), and FVD-AD (d); FVD: freeze vacuum drying; AD: air drying; FVD-AD: combined drying consisting of vacuum freeze drying and air drying.

TABle 2: Drying time, hardness, moisture content, and water activity of kiwifruits samples dried by different drying methods.

\begin{tabular}{lccccc}
\hline Drying method & Drying time $(\mathrm{h})$ & $\begin{array}{c}\text { Specific energy requirements } \\
(\mathrm{Eq})(\mathrm{kWh} / \mathrm{kg})\end{array}$ & Moisture content $(\%)$ & Water activity $\left(a_{\mathrm{w}}\right)$ & Hardness $(\mathrm{g})$ \\
\hline FVD & $42.47 \pm 0.52^{\mathrm{a}}$ & $38.23 \pm 0.73^{\mathrm{a}}$ & $3.32 \pm 0.03^{\mathrm{b}}$ & $0.3335 \pm 0.001^{\mathrm{b}}$ & $3973.70 \pm 20.17^{\mathrm{c}}$ \\
AD & $8.08 \pm 0.14^{\mathrm{c}}$ & $19.80 \pm 0.27^{\mathrm{c}}$ & $2.69 \pm 0.02^{\mathrm{d}}$ & $0.3049 \pm 0.001^{\mathrm{d}}$ & $7919.61 \pm 51.24^{\mathrm{a}}$ \\
FVD-AD & $26.24 \pm 0.32^{\mathrm{b}}$ & $24.05 \pm 0.46^{\mathrm{b}}$ & $2.91 \pm 0.02^{\mathrm{c}}$ & $0.321 \pm 0.001^{\mathrm{c}}$ & $5252.71 \pm 33.53^{\mathrm{b}}$ \\
Fresh & - & - & $87.55 \pm 1.64^{\mathrm{a}}$ & $0.993 \pm 0.002^{\mathrm{a}}$ & - \\
\hline
\end{tabular}

Note. Data are shown as the mean \pm SD $(n=3)$. Means within a column with the same letter are not significantly different as indicated by Duncan's multiple range test $(p<0.05)$. FVD: freeze vacuum drying; AD: air drying; FVD-AD: combined drying consisting of freeze vacuum drying and air drying.

kiwifruits. The hardness of $\mathrm{AD}$ products was significantly higher $(p<0.05)$ than of FVD and FVD-AD, whereas the FVD-AD products were slightly hard at $5252.71 \pm 33.53 \mathrm{~g}$, which was in between the values for FVD and AD kiwifruits. This finding was consistent with the results of moisture content and water activity. Several earlier reported samples were produced using $\mathrm{AD}$ and characterized by greater hardness $[26,27]$.
3.3. Effect of Drying Methods on the Antioxidant Components. Table 3 shows the comparison of the active composition analysis in the samples subjected to different drying methods with that in the fresh samples. Clearly, significant differences were noted among kiwifruits $(p<0.05)$. The active component contents of AA, TFC, and DPPH decreased significantly $(p<0.05)$ upon drying, and FVD samples showed the highest values, followed by FVD-AD samples. The reducing 
TABLE 3: Changes in total flavonoid and phenolic content and antioxidant activity of kiwifruits dried by different drying methods.

\begin{tabular}{|c|c|c|c|c|}
\hline & FVD & $\mathrm{AD}$ & FVD-AD & Fresh \\
\hline $\mathrm{AA}(\mathrm{mg} / 100 \mathrm{~g})$ & $234.75 \pm 14.54^{\mathrm{b}}$ & $101.51 \pm 10.98^{\mathrm{d}}$ & $183.99 \pm 5.49^{c}$ & $300.70 \pm 5.42^{\mathrm{a}}$ \\
\hline TFC (mg rutin/g d.w.) & $1.56 \pm 0.04^{\mathrm{b}}$ & $0.76 \pm 0.01^{\mathrm{d}}$ & $0.84 \pm 0.02^{\mathrm{c}}$ & $2.31 \pm 0.05^{\mathrm{a}}$ \\
\hline DPPH (\%) & $368.68 \pm 1.77^{\mathrm{b}}$ & $257.35 \pm 4.56^{\mathrm{d}}$ & $306.10 \pm 1.59^{c}$ & $424.28 \pm 0.24^{\mathrm{a}}$ \\
\hline
\end{tabular}

Note. Data are shown as the mean $\pm \mathrm{SD}(n=3)$. Means within a row with the same letter are not significantly different as indicated by Duncan's multiple range test $(p<0.05)$. FVD: freeze vacuum drying; AD: air drying; FVD-AD: combined drying consisting of freeze vacuum drying and air drying.

power could be attributed mainly to the bioactive compounds associated with antioxidant activity [28]. The contents of phenolic compounds in the tested samples may be affected by the losses due to the drying process and oxidation and also by the de novo synthesis. These results could be due to the influences of temperature and oxidation $[29,30]$. Lowtemperature processing caused minor effect on the drop of active component contents. However, high-temperature treatment led to tremendous decrease in the content of active components [31]. This was somehow consistent with the previous reports [32]. The low-oxygen and temperature environment during FVD and FVD-AD could effectively decrease the wastages of AA and flavonoids. However, compared with that in FVD treatment, FVD-AD treatment exposed more oxygen to kiwifruit samples. Moreover, in case of $\mathrm{AD}$, temperature of samples increased rapidly due to the presence of an electric heater as the sole source for providing energy. Therefore, AA and TFC of kiwifruits significantly decreased in $\mathrm{AD}$ and FVD-AD [28].

3.4. Free and Bound Water. To evaluate the water content of samples, the $T_{2}$ relaxation curves of EWP after multiexponential fitting analysis with the CPMG sequence are presented in Figure 3. Generally, the relaxation time $T_{2}$ of water was closely related to its molecular dynamics. Water with higher degrees of freedom corresponds to longer $T_{2}$ and vice versa. Consequently, different transverse relaxation time $T_{2}$ components represented water in different mobile states in ginger samples rich in water [33]. All samples showed four peaks, and these peak times are identified as $T_{21}$, $T_{22}$, and $T_{23}$, according to research. The signals in the range of $0-10 \mathrm{~ms}$ (I, $\left.T_{21}\right)$ indicated the bound water, which was closely integrated with polar groups of molecules; those in the range of $10-100 \mathrm{~ms}$ (II, $T_{22}$ ) reflected the immobilized water; and those within the limits of $100-1000 \mathrm{~ms}$ (III, $T_{23}$ ) represented the free water [34]. This allowed the separate observation on raw kiwifruit tissue of extracellular space, cell wall, cytoplasm, and vacuole, together with their modifications upon technological treatments [35]. As shown in Table 4, in raw material, water was found to be distributed as follows: $86.15 \pm 2.37 \%$ in vacuole $\left(T_{23} 1072.26 \pm 14.12 \mathrm{~ms}\right)$, $9.98 \pm 0.26 \%\left(T_{22} 75.64 \pm 0.31 \mathrm{~ms}\right)$ in cytoplasm/extracellular space, and $3.88 \pm 0.36 \%\left(T_{21} 1.52 \pm 0.02 \mathrm{~ms}, 8.11 \pm 0.02 \mathrm{~ms}\right)$ was ascribed to the structural water of the cell wall. The significance $(p<0.05)$ was surveyed in $A_{21}, A_{22}$, and $A_{23}$ between the fresh and the dried samples. The transverse relaxation time of free water and immobilized water reduced significantly in the dried samples (Figure 2), indicating that their mobility decreased gradually and drying treatment

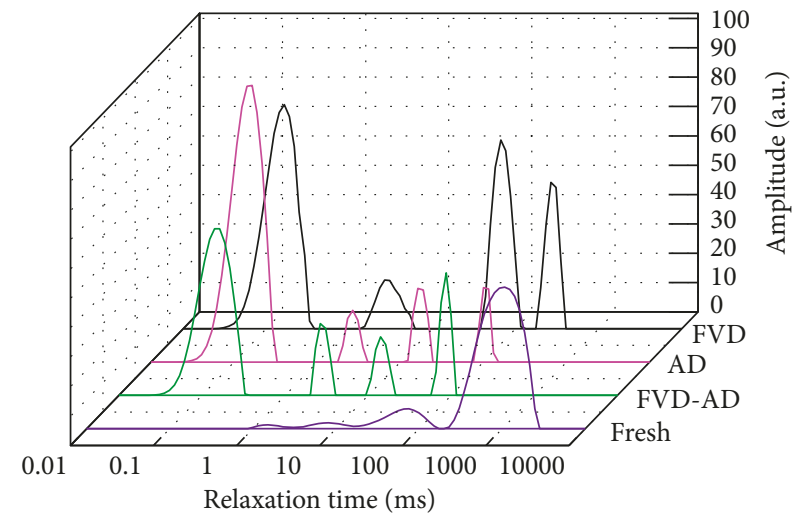

FIgURE 3: LF-NMR $T_{2}$ relaxation time distribution curves of samples. FVD: freeze vacuum drying; $\mathrm{AD}$ : air drying; FVD-AD: combined drying consisting of vacuum freeze drying and air drying.

restricted water mobility. The $T_{21}$ fractions representing bound water of $\mathrm{AD}$ samples accounted for $84.398 \% \pm 1.30 \%$ of the total signal, which was higher than the other samples, followed by FVD-AD samples $(75.494 \% \pm 0.42 \%)$ and last, the FVD samples. This could indicate that tonoplast integrity was compromised increasing the exchange of water between cell vacuole and extracellular/cytoplasm volumes in the drying process [36]. This was in accordance with the difference in the amount of the NMR signal (or in other words, in the amount of water) associated to the peaks.

3.5. E-Nose Analysis. In order to legibly describe the aroma profile of kiwifruits, a PCA plot was performed (Figure 4(a)). Electronic nose combined with PCA can be used to distinguish the flavor characteristics of kiwifruit according to different drying methods. The discrimination index was 92 , and the score plots of kiwifruit showed that the first principal component (PC 1) accounted for $99.196 \%$, whereas the second principal component (PC 2) accounted for $0.3573 \%$. The cumulative contribution of the first two PC variances was $99.553 \%$, which was enough to represent variables. According to Figure 4(a), the fresh and FVD-AD samples appeared on the negative electrodes of PC 1 and PC 2, but samples of $\mathrm{AD}$ showed the opposite. At the same time, FVD samples appeared on the negative side of PC 1 and the positive side of PC 2. The region of fresh samples was close to the FVD-AD, indicating that possible similarities could be present among these samples.

The raw response data generated by the 18 sensors of the electronic nose were collected and converted into radar graphs as shown in Figure 4(b). Generally speaking, the 


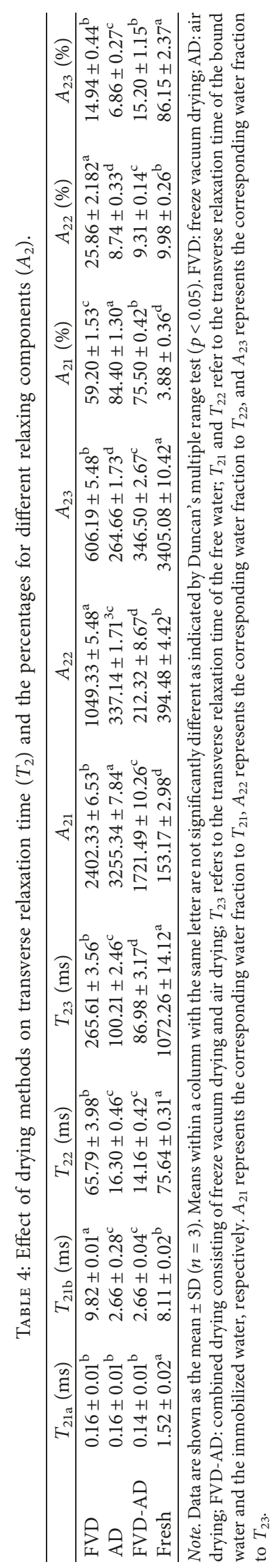




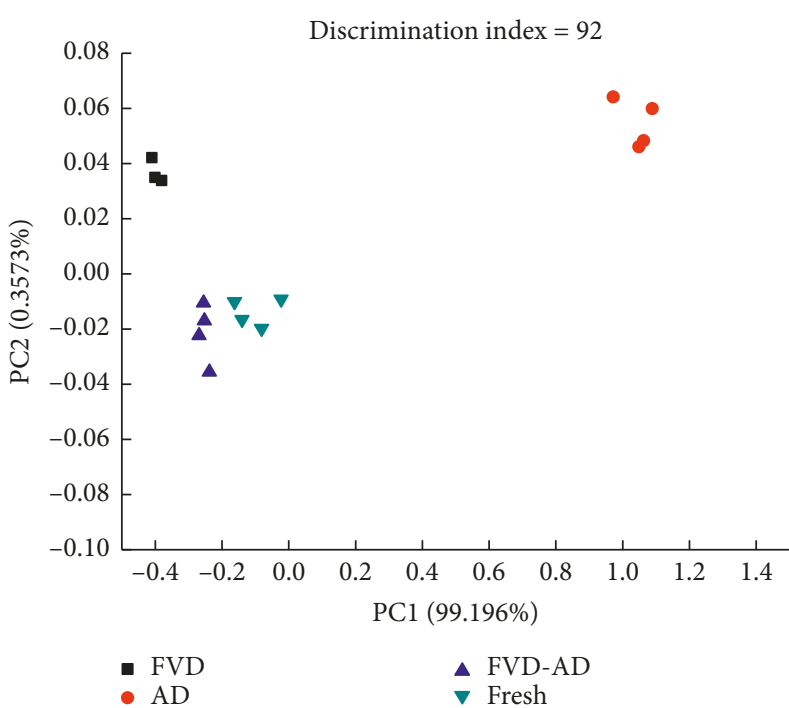

(a)

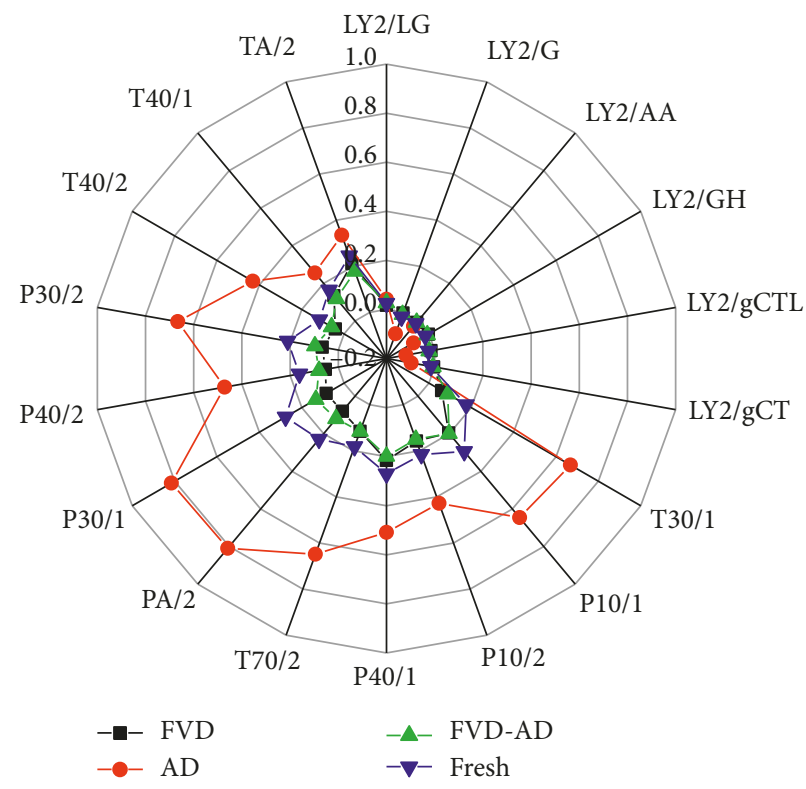

(b)

FIgURE 4: (a) PCA results of kiwifruit samples. (b) Radar map of kiwifruit samples. Note: FVD, freeze vacuum drying; AD, air drying; FVD$\mathrm{AD}$, combined drying consisting of freeze vacuum drying and air drying. Sensors: 1: LY2/LG; 2: LY2/G; 3: LY2/AA; 4: LY2/GH; 5: LY2/ gCTL; 6: LY2/gCT; 7:T30/1; 8: P10/1; 9: P10/2; 10: P40/1; 11: T70/2; 12: PA/2; 13: P30/1; 14: P40/2; 15: P30/2; 16: T40/2; 17: T40/1; 18: TA/2.

similar shapes of these radar graphs implied the similarity of these samples from different drying methods. Results suggested that the fingerprints outlined the fresh samples during the drying period. The relative values of P30/2 (alcohol), P30/1 (solvents), PA/2 (ammonia, amines), and P10/1 (hydrocarbons, methane) of fresh samples were significantly lower than of the dried samples. Moreover, a radar fingerprint chart of fresh samples and FVD-AD samples almost overlapped, indicating that similar volatile ingredients existed in these samples. Pei et al. [37] reported that the odors in button mushroom dehydrated by FVD were significantly lost than those by freeze vacuum combined drying, which was consistent with our result.

3.6. Effect of Drying Methods on Microstructure. Figure 5 shows cross-sectional SEM images of dry kiwifruits that were dried with FVD, AD, and FVD-AD (Figures 5(a)-5(c)). Generally, the microstructural change during kiwifruit dehydration was related to the water migration of cells. This phenomenon caused cell stress and turgor loss, resulting in contraction and structural collapse at different levels. The surface structures of the AD samples were tightly shrunk and flattened, while those of the FVD-AD samples showed less shrinkage, and the bowl-shaped structure of the cell walls was maintained. A similar honeycomb network was observed in the FD sample, which exhibited the least amount of tissue shrinkage or cell collapse. The cell walls of freeze-dried samples appeared to be comparatively smooth and thin, explaining the noncrisp and spongy texture obtained by freeze-dried kiwifruits [38]. These phenomena occurred because the samples of FVD and FVD-AD were in vacuum and could easily generate porous structures. In addition, the
FVD samples had the lowest hardness because the material was frozen during drying; Therefore, it reduced cell damage and had a porous honeycomb structure with weak force resistance [39]. Moreover, the kiwifruits dried by FVD-AD had a more porous and less collapsed structure, compared with those of FVD samples because the FVD-AD sample was heated by hot air and water evaporated more rapidly, resulting in puffing and creating larger pores within the samples [40]. The larger pore size and higher porosity allowed this sample to absorb more water during rehydration.

3.7. PCA. Three drying methods for kiwifruit samples were evaluated by exploratory PCA technology. The physical and chemical properties and oxidation resistance of any cluster were evaluated. The color index was expressed by $\Delta E$, and the drying efficiency index was expressed by drying time. As shown in Figure 6, the cumulative contribution of PC 1 and PC 2 accounts for $93.16 \%$ of the total variance $(\mathrm{PC} 1=87.34 \%, \mathrm{PC} 2=8.81 \%)$. PC 1 was highly correlated with $\Delta E(-0.876), A_{23}(0.897)$, water activity $(0.910)$, AA (0.968), TFC (0.967), and DPPH (0.962). PC 2 was mainly correlated with TPC (0.541), $A_{23}(-0.438)$, and $a_{\mathrm{w}}(-0.412)$.

The PC 1 and PC 2 scores of fresh samples were considerably the highest among the other drying methods because they had higher contents of AA and TFC, as well as higher antioxidant activity. The factor score of fresh samples was the highest (2.07), followed by FVD-AD samples $(-0.81)$ and FVD samples $(-0.90)$. Meanwhile, the sample of AD showed the lowest factor score $(-5.22)$. Therefore, AD samples were negatively correlated with $\mathrm{PC} 1$ and PC2, representing that $\mathrm{AD}$ had a negative effect on the active 

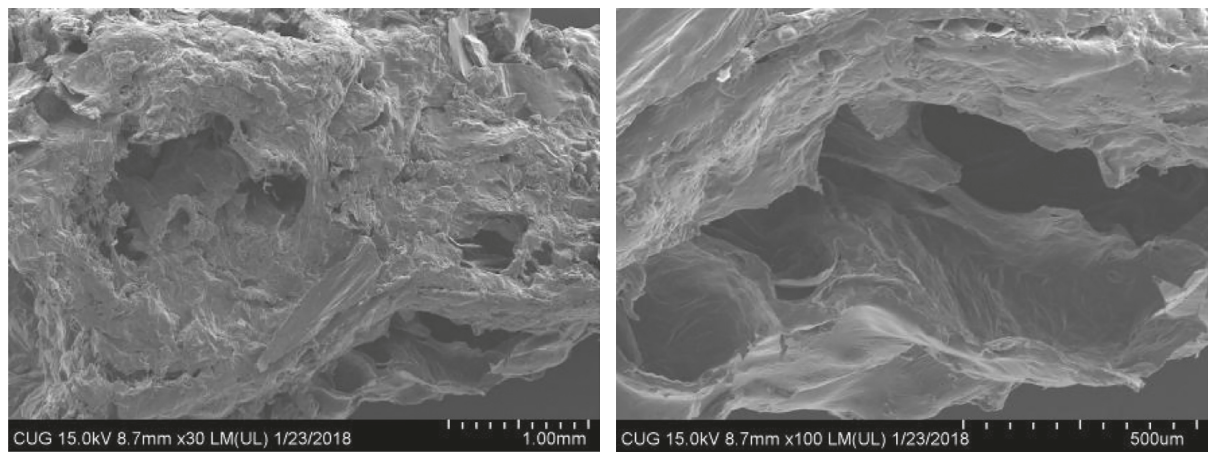

(a)
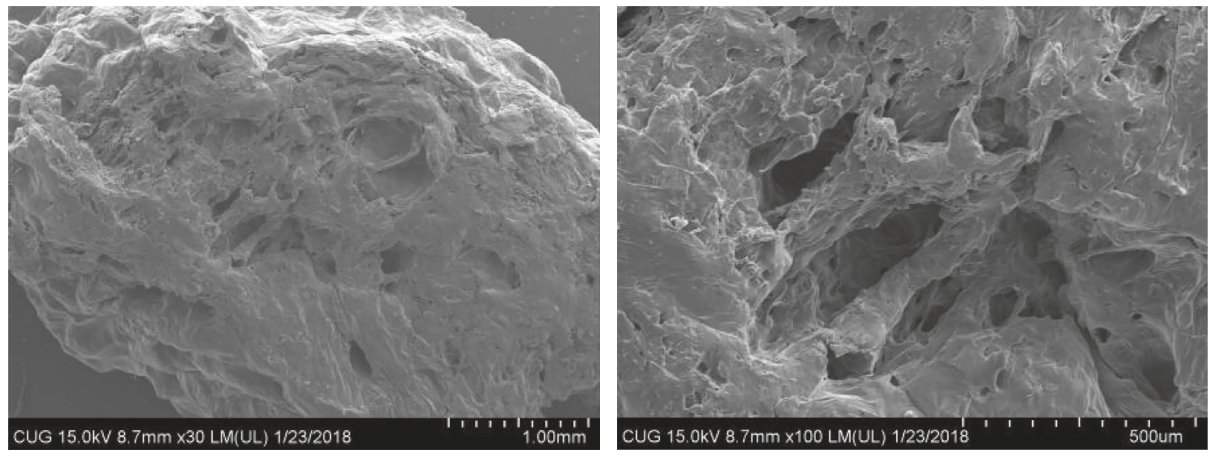

(b)
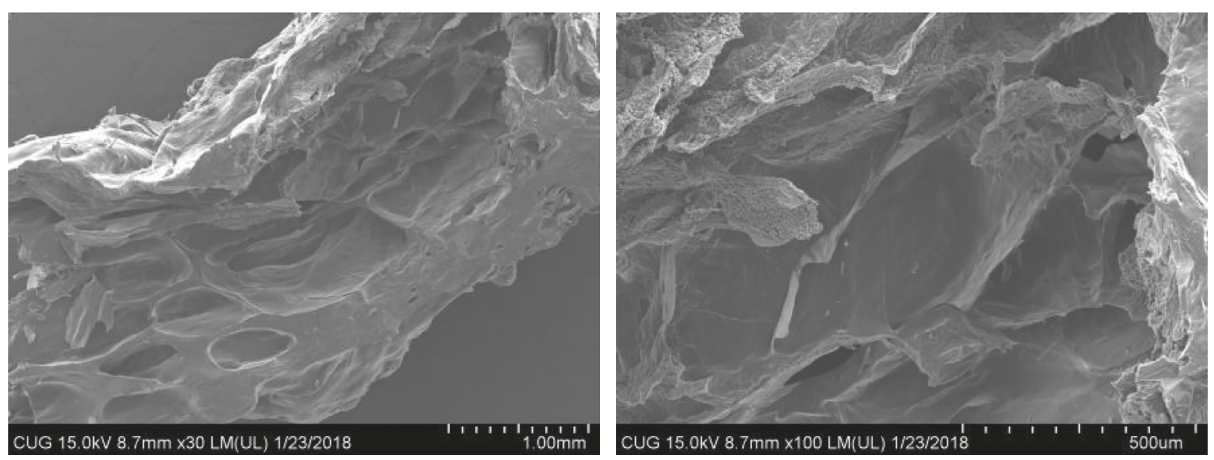

(c)

FiguRE 5: Scanning electron micrographs of kiwifruit samples dried by FVD (a), AD (b), FVD-AD (c). FVD, freeze vacuum drying; AD, air drying; FVD-AD, combined drying consisting of freeze vacuum drying and air drying.

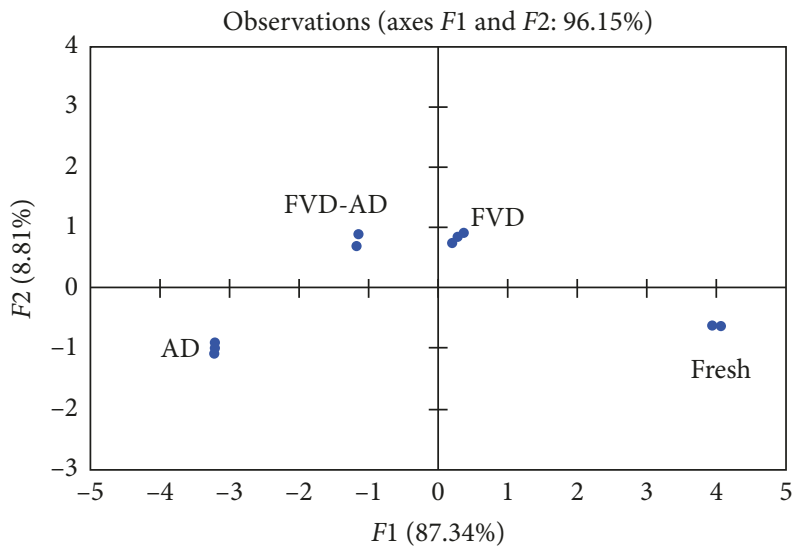

Figure 6: Principal component analysis plot of data for different sensory quality, antioxidant properties, and drying efficiency of kiwifruit samples. FVD: freeze vacuum drying; AD: air drying; FVD-AD: combined drying consisting of freeze vacuum drying and air drying; 
components, antioxidant activity, and color quality. The FVD process was positively correlated with PC1 and PC2, representing that it had a significant effect on the antioxidant activity of kiwifruits. However, the FVD-AD process was negatively correlated with PC2 and positively correlated with PC1 because it had negative effects on water activity and free water and positive effects on TPC, AA, DPPH, and color.

\section{Conclusion}

The application of FVD-AD in the drying of kiwifruit was evaluated. Compared with the AD method, the FVD-AD method yielded more active component contents of AA, TFC, and antioxidant properties. The color of FVD-AD product was close to that of fresh kiwifruit. According to cluster analysis, it was proved that the volatile compounds of FVD-AD products were more similar with those of fresh ones compared to FVD and $\mathrm{AD}$ products. In addition, the application of FVD-AD contributed to form porous microstructure in dried kiwifruits. The total drying time of FVD-AD was $38.22 \%$ lower than that of FVD, and the bound water of FVD-AD was more than that of FVD. From the perspectives of color, energy consumption, moisture, odors, and microstructure, FVD-AD was the most promising processing method for functional kiwifruit snacks.

\section{Data Availability}

The data used to support the findings of this study are included within the article.

\section{Conflicts of Interest}

The authors declare that there are no conflicts of interest regarding the publication of this paper.

\section{Acknowledgments}

The authors appreciate the financial support provided by the National Key Research and Development Plan (2017YFD0400900 and 2017YFD0400904).

\section{References}

[1] N. Değirmencioğlu, O. Gürbüz, E. N. Herken, and A. Y. Y1ld1z, "The impact of drying techniques on phenolic compound, total phenolic content and antioxidant capacity of oat flour tarhana," Food Chemistry, vol. 194, pp. 587-594, 2016.

[2] H. P. Castro, P. M. Teixeira, and R. Kirby, "Evidence of membrane damage in Lactobacillus bulgaricus following freeze drying," Journal of Applied Microbiology, vol. 82, no. 1, pp. 87-94, 1997.

[3] C. Ratti, "Hot air and freeze-drying of high-value foods: a review," Journal of Food Engineering, vol. 49, no. 4, pp. 311319, 2001.

[4] L. Yu, M. S. Turner, M. Fitzgerald, J. R. Stokes, and T. Witt, "Review of the effects of different processing technologies on cooked and convenience rice quality," Trends in Food Science and Technology, vol. 59, pp. 124-138, 2017.
[5] H. Jiang, M. Zhang, Y. Liu, A. S. Mujumdar, and H. Liu, "The energy consumption and color analysis of freeze/microwave freeze banana chips," Food and Bioproducts Processing, vol. 91, no. 4, pp. 464-472, 2013.

[6] X. Tang and M. J. Pikal, "Design of freeze-drying processes for pharmaceuticals: practical advice," Pharmaceutical Research, vol. 21, no. 2, pp. 191-200, 2004.

[7] Y. Xu, M. Zhang, D. Tu, J. Sun, L. Zhou, and A. S. Mujumdar, "A two-stage convective air and vacuum freeze-drying technique for bamboo shoots," International Journal of Food Science and Technology, vol. 40, no. 6, pp. 589-595, 2005.

[8] G. Donsì, G. Ferrari, R. Nigro, and P. DI Matteo, "Combination of mild dehydration and freeze-drying processes to obtain high quality dried vegetables and fruits," Food and Bioproducts Processing, vol. 76, no. 4, pp. 181-187, 1998.

[9] F. Pei, W. J. Yang, Y. Shi et al., "Comparison of freeze-drying with three different combinations of drying methods and their influence on colour, texture, microstructure and nutrient retention of button mushroom (Agaricus bisporus) slices," Food and Bioprocess Technology, vol. 7, no. 3, pp. 702-710, 2013.

[10] A. Saxena, T. Maity, P. S. Raju, and A. S. Bawa, "Optimization of pretreatment and evaluation of quality of jackfruit (Artocarpus heterophyllus) bulb crisps developed using combination drying," Food and Bioproducts processing, vol. 95, pp. 106-117, 2015.

[11] H. S. P. Kumar, K. Radhakrishna, P. K. Nagaraju, and D. V. Rao, "Effect of combination drying on the physicochemical characteristics of carrot and pumpkin," Journal of Food Processing and Preservation, vol. 25, no. 6, pp. 447-460, 2001.

[12] A. Heredia, C. Barrera, and A. Andrés, "Drying of cherry tomato by a combination of different dehydration techniques. Comparison of kinetics and other related properties," Journal of Food Engineering, vol. 80, no. 1, pp. 111-118, 2007.

[13] L. L. Huang, M. Zhang, L. P. Wang, A. S. Mujumdar, and D. F. Sun, "Influence of combination drying methods on composition, texture, aroma and microstructure of apple slices," LWT-Food Science and Technology, vol. 47, no. 1, pp. 183-188, 2012.

[14] H. J. Park, Y. Lee, and J. B. Eun, "Physicochemical characteristics of kimchi powder manufactured by hot air drying and freeze drying," Biocatalysis and Agricultural Biotechnology, vol. 5, pp. 193-198, 2016.

[15] A. Wojdyło, A. Figiel, and J. Oszmiański, "Effect of drying methods with the application of vacuum microwaves on the bioactive compounds, color, and antioxidant activity of strawberry fruits," Journal of Agricultural and Food Chemistry, vol. 57, no. 4, pp. 1337-1343, 2009.

[16] S. K. Jagota and H. M. Dani, "A new colorimetric technique for the estimation of vitamin c using folin phenol reagent," Analytical Biochemistry, vol. 127, no. 1, pp. 178-182, 1982.

[17] K. An, D. Zhao, Z. Wang, J. Wu, Y. Xu, and G. Xiao, "Comparison of different drying methods on Chinese ginger (Zingiber officinale Roscoe): changes in volatiles, chemical profile, antioxidant properties, and microstructure," Food Chemistry, vol. 197, pp. 1292-1300, 2016.

[18] J. H. Park, G. I. Jeon, J. M. Kim, and E. Park, “Antioxidant activity and antiproliferative action of methanol extracts of 4 different colored bell peppers (Capsicum annuum L.)," Food Science and Biotechnology, vol. 21, no. 2, pp. 543-550, 2012.

[19] W. Kalt, "Effects of production and processing factors on major fruit and vegetable antioxidants," Journal of Food Science, vol. 70, no. 1, pp. R11-R19, 2005. 
[20] T. M. Lin, D. T. Durance, and C. H. Scaman, "Characterization of vacuum microwave, air and freeze dried carrot slices," Food Research International, vol. 31, no. 2, pp. 111-117, 1998.

[21] M. Maskan, "Drying, shrinkage and rehydration characteristics of kiwifruits during hot air and microwave drying," Journal of Food Engineering, vol. 48, no. 2, pp. 177-182, 2001.

[22] C. Kumar, M. A. Karim, and M. U. H. Joardder, "Intermittent drying of food products: a critical review," Journal of Food Engineering, vol. 121, no. 1, pp. 48-57, 2014.

[23] Q. G. Hu, M. Zhang, A. S. Mujumdar, G. N. Xiao, and S. Jincai, "Drying of edamames by hot air and vacuum microwave combination," Journal of Food Engineering, vol. 77, no. 4, pp. 977-982, 2006.

[24] Y. Su, M. Zhang, and A. S. Mujumdar, "Recent developments in smart drying technology," Drying Technology, vol. 33, no. 3, pp. 260-276, 2014.

[25] A. K. Jaiswal, N. Abu-Ghannam, and S. Gupta, "A comparative study on the polyphenolic content, antibacterial activity and antioxidant capacity of different solvent extracts of Brassica oleracea vegetables," International Journal of Food Science and Technology, vol. 47, no. 2, pp. 223-231, 2011.

[26] N. Jiang, C. Liu, D. Li et al., "Evaluation of freeze drying combined with microwave vacuum drying for functional okra snacks: antioxidant properties, sensory quality, and energy consumption," LWT-Food Science and Technology, vol. 82, pp. 216-226, 2017.

[27] G. Rajkumar, S. Shanmugam, M. D. S. Galvâo et al., "Comparative evaluation of physical properties and volatiles profile of cabbages subjected to hot air and freeze drying," LWT, vol. 80, pp. 501-509, 2017.

[28] P. Suvarnakuta, C. Chaweerungrat, and S. Devahastin, "Effects of drying methods on assay and antioxidant activity of xanthones in mangosteen rind," Food Chemistry, vol. 125, no. 1, pp. 240-247, 2011.

[29] S. N. Lou, Y. C. Lai, J. D. Huang, C. T. Ho, L. H. A. Ferng, and Y. C. Chang, "Drying effect on flavonoid composition and antioxidant activity of immature kumquat," Food Chemistry, vol. 171, pp. 356-363, 2015.

[30] I. Hamrouni-Sellami, F. Z. Rahali, I. B. Rebey, S. Bourgou, F. Limam, and B. Marzouk, "Total phenolics, flavonoids, and antioxidant activity of sage (Salvia officinalis L.) plants as affected by different drying methods," Food and Bioprocess Technology, vol. 6, no. 3, pp. 806-817, 2012.

[31] V. Dewanto, X. Wu, K. K. Adom, and R. H. Liu, “Thermal processing enhances the nutritional value of tomatoes by increasing total antioxidant activity," Journal of Agricultural and Food Chemistry, vol. 50, no. 10, pp. 3010-3014, 2002.

[32] M. Khraisheh, W. A. M. McMinn, and T. R. A. Magee, "Quality and structural changes in starchy foods during microwave and convective drying," Food Research International, vol. 37, no. 5, pp. 497-503, 2004.

[33] C. Huang, Q. Zhou, S. Gao, Q. Bao, F. Chen, and C. Liu, "Time-domain nuclear magnetic resonance investigation of water dynamics in different ginger cultivars," Journal of Agricultural and Food Chemistry, vol. 64, no. 2, pp. 470-477, 2016.

[34] M. Li, H. Wang, G. Zhao et al., "Determining the drying degree and quality of chicken jerky by LF-NMR," Journal of Food Engineering, vol. 139, pp. 43-49, 2014.

[35] M. A. Mauro, N. Dellarosa, U. Tylewicz et al., "Calcium and ascorbic acid affect cellular structure and water mobility in apple tissue during osmotic dehydration in sucrose solutions," Food Chemistry, vol. 195, pp. 19-28, 2016.
[36] U. Tylewicz, K. Aganovic, M. Vannini et al., "Effect of pulsed electric field treatment on water distribution of freeze-dried apple tissue evaluated with DSC and TD-NMR techniques," Innovative Food Science and Emerging Technologies, vol. 37, pp. 352-358, 2016.

[37] F. Pei, W. Yang, N. Ma et al., "Effect of the two drying approaches on the volatile profiles of button mushroom (Agaricus bisporus) by headspace GC-MS and electronic nose," LWT-Food Science and Technology, vol. 72, pp. 343350, 2016.

[38] P. W. Y. Sham, C. H. Scaman, and T. D. Durance, "Texture of vacuum microwave dehydrated apple chips as affected by calcium pretreatment, vacuum level, and apple variety," Journal of Food Science, vol. 66, no. 9, pp. 1341-1347, 2001.

[39] P. Liu, M. Zhang, and A. S. Mujumdar, "Comparison of three microwave-assisted drying methods on the physiochemical, nutritional and sensory qualities of re-structured purplefleshed sweet potato granules," International Journal of Food Science and Technology, vol. 47, no. 1, pp. 141-147, 2011.

[40] A. Nathakaranakule, P. Jaiboon, and S. Soponronnarit, "Farinfrared radiation assisted drying of longan fruit," Journal of Food Engineering, vol. 100, no. 4, pp. 662-668, 2010. 


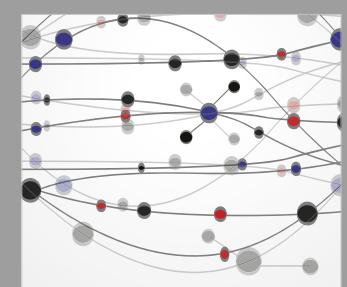

The Scientific World Journal
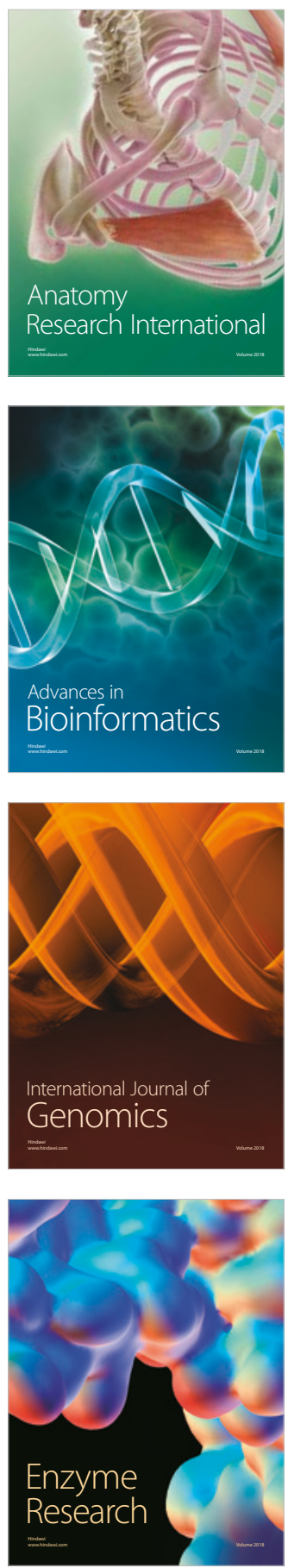
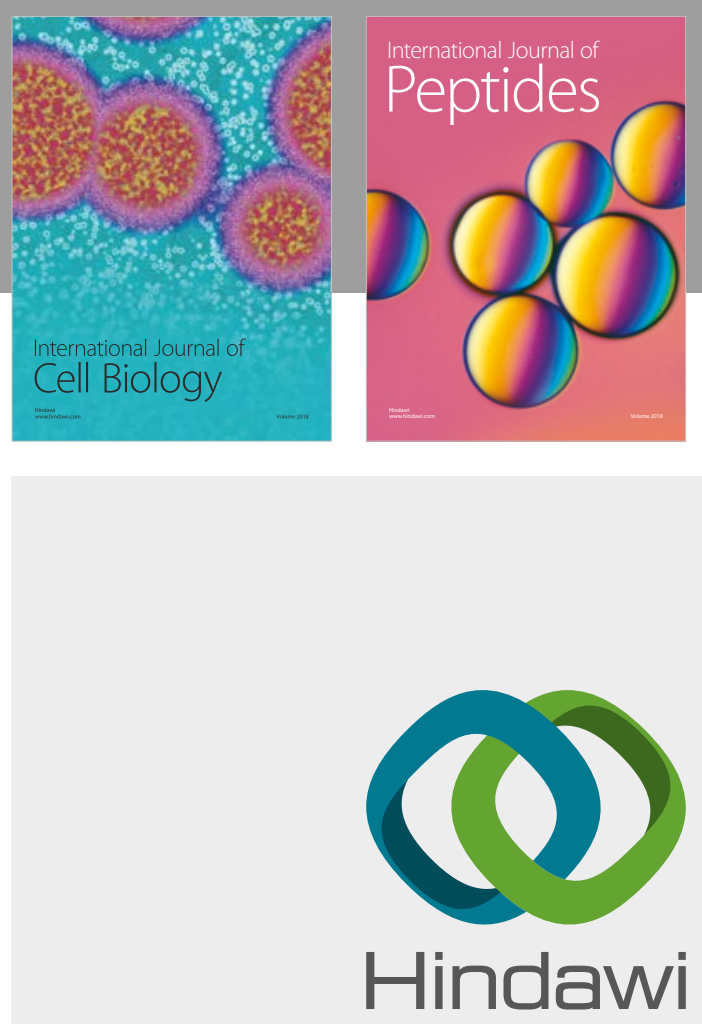

Submit your manuscripts at

www.hindawi.com
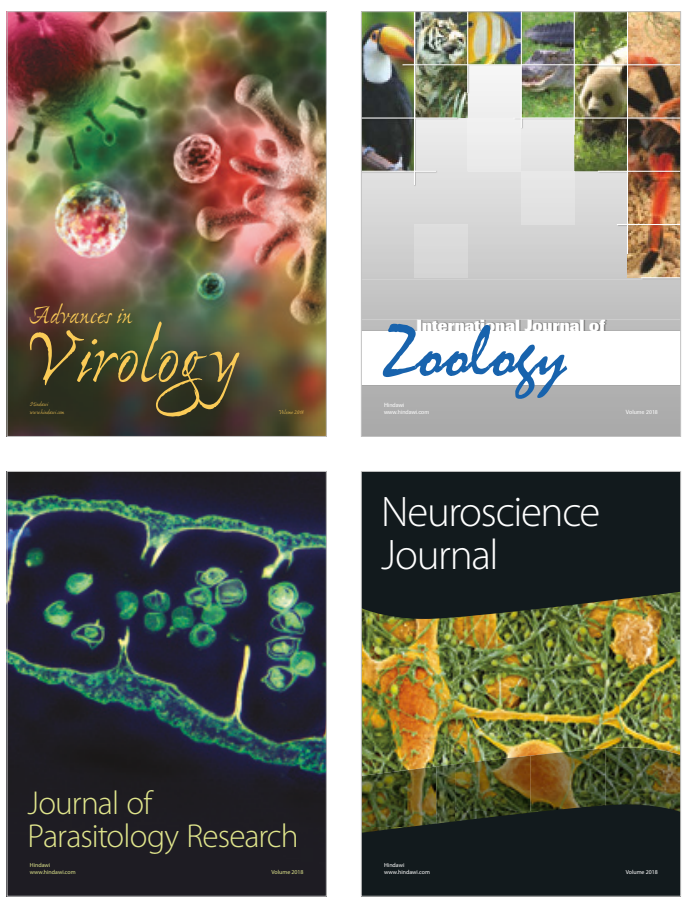
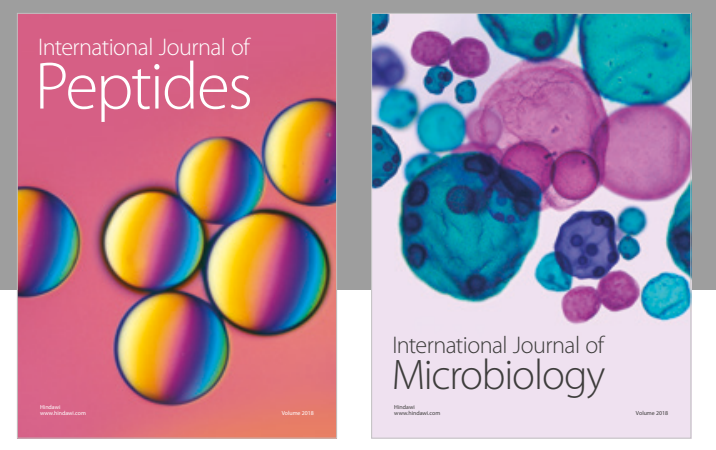

nternational Journal of Microbiology
Journal of
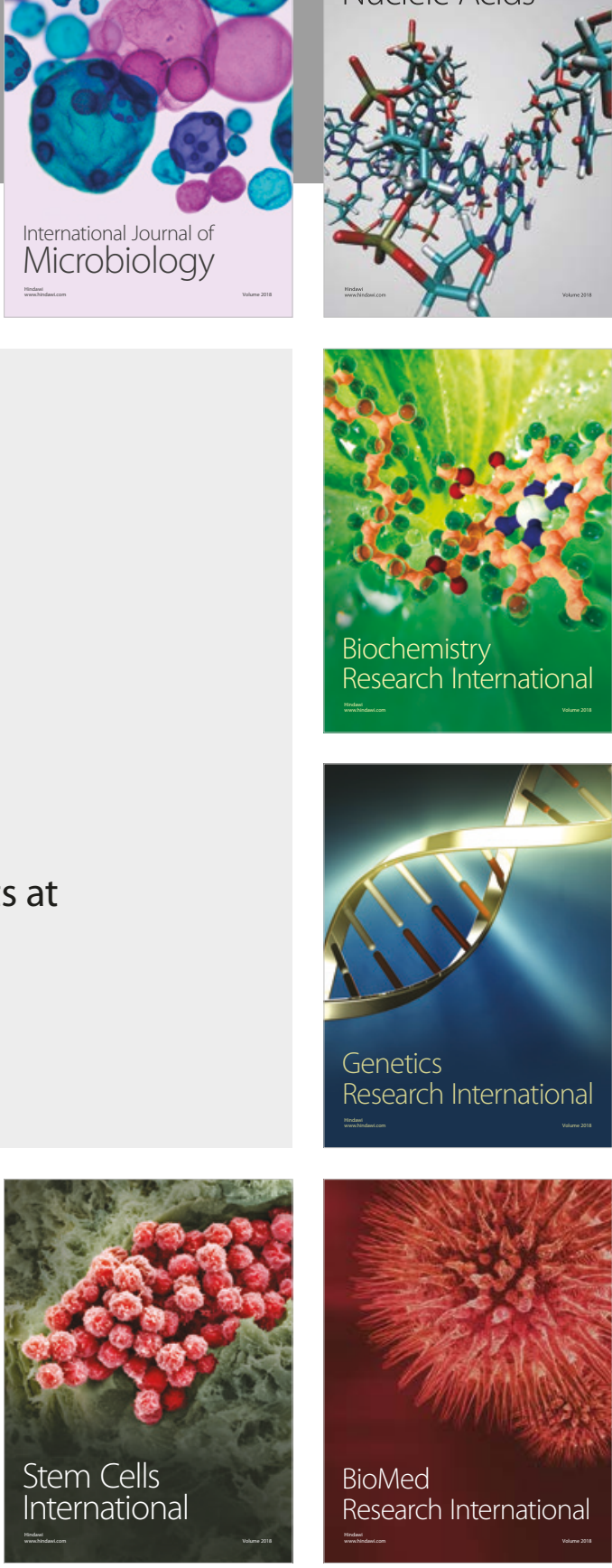
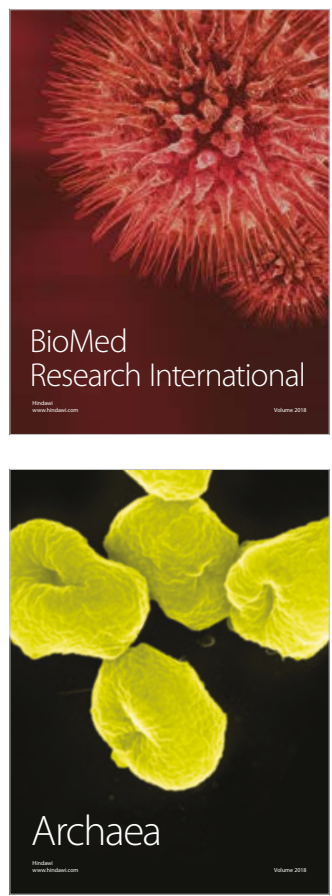